13.1;13.3

\title{
Воздействие дуплексной обработки на механические свойства нержавеющей стали марки 316L
}

\author{
(C) А.С. Гренадёров, А.А. Соловьёв, К.В. Оскомов \\ Институт сильноточной электроники СО РАН, Томск, Россия \\ E-mail: 1711Sasha@mail.ru
}

Поступило в Редакцию 3 июля 2020 г.

В окончательной редакции 3 июля 2020 г.

Принято к публикации 24 июля 2020 г.

\begin{abstract}
Представлены результаты экспериментальных исследований по модифицированию поверхностного слоя стали марки 316L дуплексной обработкой, включающей в себя ионно-плазменную обработку в атмосфере азота с последующим нанесением углеводородных пленок, легированных кремнием и кислородом $\left(a-\mathrm{C}: \mathrm{H}: \mathrm{SiO}_{x}\right)$, методом плазмохимического осаждения. Механические свойства поверхности стали (твердость, модуль упругости, индекс пластичности, сопротивление пластической деформации) определялись методом наноиндентирования, а адгезия пленок оценивалась методом скретч-теста. Установлено, что наибольшее улучшение механических свойств системы пленка-подложка наблюдалось после нанесения пленки $a-\mathrm{C}: \mathrm{H}: \mathrm{SiO}_{x}$ на предварительно упрочненную посредством ионно-плазменной обработки в плазме азота поверхность.
\end{abstract}

Ключевые слова: плазменная обработка, алмазоподобный углерод, пленки $a$-C : $\mathrm{H}: \mathrm{SiO}_{x}$, твердость, адгезия.

DOI: 10.21883/PJTF.2020.21.50189.18452

Для создания более $60 \%$ медицинских имплантатов используются металлические материалы (нержавеющая сталь, сплавы на основе титана и кобальта и т.д.) [1]. Это обусловлено их высокими прочностными характеристиками: предел текучести и предел усталости (по сравнению с керамикой и полимерами). Однако входящие в их состав химические элементы (Al, V, Ni, $\mathrm{Co}, \mathrm{Cr}$ ) вызывают токсические и аллергические реакции организма. Кроме того, низкая износостойкость этих материалов приводит к образованию металлических осколков в местах контакта трущихся деталей искусственного сустава. Для решения этих проблем на поверхность металлического материала наносят биосовместимые и износостойкие покрытия [2]. Для этой цели отлично подходят алмазоподобные углеродные пленки (DLC), обладающие высокой твердостью (до 50-70 GPa) и износостойкостью, а также биосовместимостью [2,3]. Однако недостатком DLC являются высокие внутренние напряжения (до $7 \mathrm{GPa}$ ), снижающие адгезию покрытий и срок их эксплуатации [4].

Углеводородные пленки, легированные кремнием и кислородом $\left(a-\mathrm{C}: \mathrm{H}: \mathrm{SiO}_{x}\right)$, являются одной из разновидностей алмазоподобного углерода. Это аморфный материал, состоящий из взаимопроникающих матриц $a-\mathrm{C}: \mathrm{H}$ и $a-\mathrm{Si}: \mathrm{O}$. Такой материал обладает низкими внутренними напряжениями $(\leq 1 \mathrm{GPa})$, высокой твердостью до $20 \mathrm{GPa}[5,6]$, низкими значениями скорости износа $\left(\sim 10^{-7} \mathrm{~mm}^{3} / \mathrm{N} \cdot \mathrm{m}\right)$ и коэффициента трения $(\sim 0.15)$ [7], а также совместимостью с биологической средой человека [8].

Недостатком твердых и сверхтвердых покрытий, наносимых на относительно „мягкие“ подложки, является их высокая хрупкость. Она проявляется при существенной деформации основы в ходе эксплуатации. Поэтому для решения данной проблемы используется предварительное упрочнение поверхности за счет ее диффузионного насыщения углеродом или азотом. В работе [9] было показано, что после цементации нержавеющей стали марки AISI 316L твердость ее поверхности увеличилась более чем в 3 раза. Это позволило повысить адгезию наносимой затем пленки $a-\mathrm{C}: \mathrm{H}$, в частности увеличить критическую нагрузку при скретч-тесте с 12 до $49 \mathrm{~N}$. В работе [10] твердость поверхности этой же стали перед нанесением DLC-покрытия была увеличена более чем в 2 раза посредством азотирования.

Цель настоящей работы заключается в исследовании изменений механических характеристик поверхности нержавеющей стали марки $316 \mathrm{~L}$ в результате нанесения пленок $a-\mathrm{C}: \mathrm{H}: \mathrm{SiO}_{x}$ и установлении влияния предварительной обработки в плазме азота на свойства данной системы пленка-подложка.

Для обработки образцов использовалась вакуумная установка объемом $\sim 0.2 \mathrm{~m}^{3}$, подробно описанная в [11]. Установка оснащена плазмогенератором с накаленным катодом, генерирующим объемную плазму, используемым как для предварительной обработки образцов в плазме азота, так и для нанесения пленки $a-\mathrm{C}: \mathrm{H}: \mathrm{SiO}_{x}$. В качестве подложек использовались пластины из нержавеющей стали марки 316L (российский аналог сталь $03 \mathrm{X} 17 \mathrm{H} 14 \mathrm{M} 3)$ размером $15 \times 15 \times 2 \mathrm{~mm}$. Поверхность подложек предварительно шлифовалась наждачной бумагой зернистостью P1000 (ISO-6344) и очищалась в ультразвуковой ванне, наполненной изопропиловым спиртом, а затем ацетоном и дистиллированной 
Механические характеристики образцов стали марки $316 \mathrm{~L}$

\begin{tabular}{l|c|c|c|c|c}
\hline \multicolumn{1}{c|}{ Образец } & $H, \mathrm{GPa}$ & $E, \mathrm{GPa}$ & $H / E$ & $H^{3} / E^{2}, \mathrm{MPa}$ & $W_{e}, \%$ \\
\hline Исходный & $5.50 \pm 0.03$ & $191 \pm 5$ & 0.030 & 4.7 & 25 \\
После обработки в плазме азота & $15.6 \pm 0.4$ & $213 \pm 6$ & 0.073 & 84 & 60 \\
После нанесения пленки $a-\mathrm{C}: \mathrm{H}: \mathrm{SiO}_{x}$ & $15.1 \pm 0.3$ & $152 \pm 3$ & 0.100 & 150 & 82 \\
После дуплексной обработки & $19.2 \pm 0.6$ & $163 \pm 9$ & 0.118 & 266 & 95
\end{tabular}
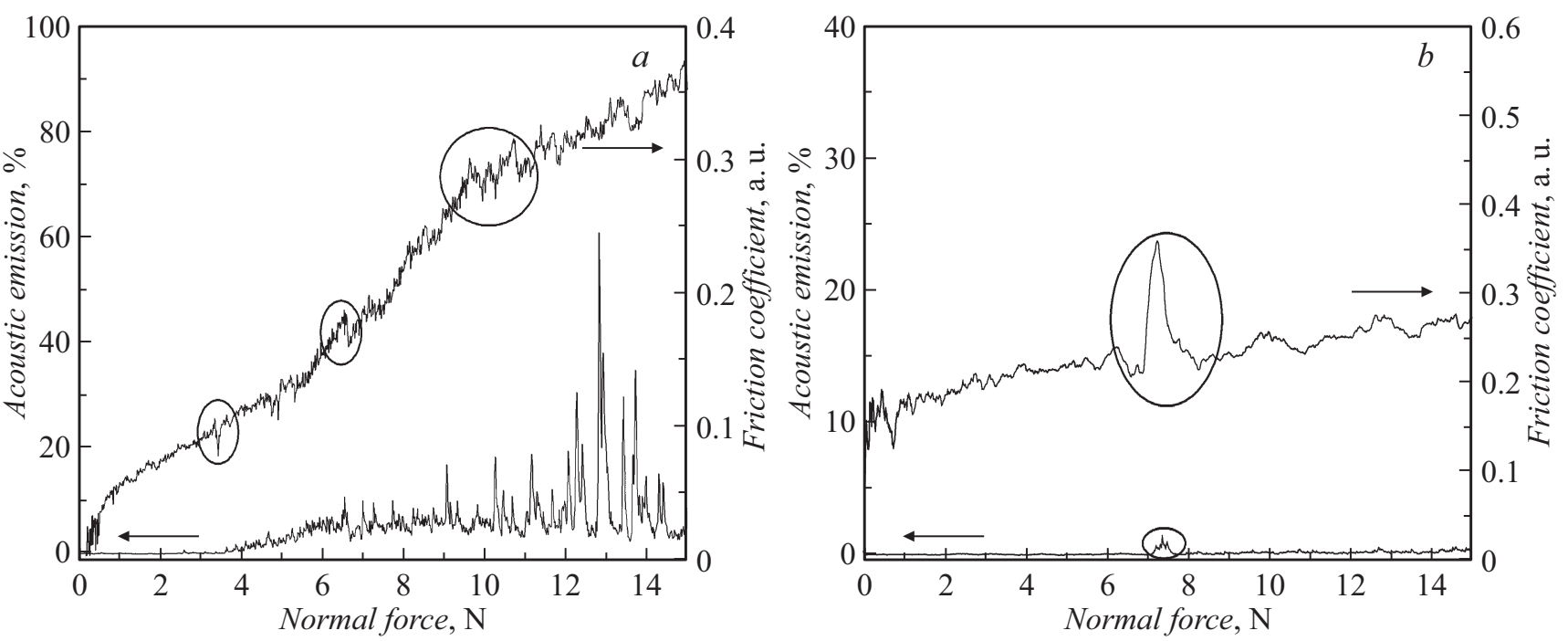

Рис. 1. Зависимости сигнала с датчика акустической эмиссии и коэффициента трения от приложенной нагрузки при скретч-тесте пленок $a$-C : H : $\mathrm{SiO}_{x}$, нанесенных на образцы стали 316L. $a-$ без предварительной обработки образцов в плазме азота, $b-\mathrm{c}$ предварительной обработкой в плазме азота.

водой. Время обработки в каждой жидкости составляло $10 \mathrm{~min}$. После этого образцы устанавливались в вакуумную камеру, которая откачивалась до остаточного давления $10^{-2} \mathrm{~Pa}$. Нанесение пленки $a-\mathrm{C}: \mathrm{H}: \mathrm{SiO}_{x}$ толщиной $2 \mu \mathrm{m}$ осуществлялось при рабочем давлении $0.1 \mathrm{~Pa}$ в смеси аргона и паров полифенилметилсилоксана при температуре подложки не более $200^{\circ} \mathrm{C}$. При этом на подложкодержатель подавалось импульсное биполярное напряжение смещения с амплитудой отрицательного импульса $300 \mathrm{~V}$ и частотой $100 \mathrm{kHz}$. Часть образцов перед нанесением покрытия обрабатывалась в плазме азота при давлении $0.3 \mathrm{~Pa}$. В этом случае на подложкодержатель подавалось напряжение смещения с амплитудой отрицательного импульса $1000 \mathrm{~V}$. Температура подложки в процессе ионно-плазменной обработки длительностью $1.5 \mathrm{~h}$ составляла $300 \pm 15^{\circ} \mathrm{C}$.

Твердость $H$ и модуль упругости $E$ образцов определялись по методике Оливера-Фарра с использованием наноиндентора NanoTest 600 (Micro Materials Ltd., GB) при нагрузке на индентор $10 \mathrm{mN}$. Адгезия пленок $a$-C : $\mathrm{H}: \mathrm{SiO}_{x}$ измерялась методом скретч-теста на приборе Micro-Scratch Tester MST-S-AX-0000 (CSEM, Швейцария) с алмазным индентором, имеющим радиус острия $100 \mu \mathrm{m}$. Максимальная нагрузка на индентор составляла $15 \mathrm{~N}$, а длина царапины $7 \mathrm{~mm}$. Скорость нагру- жения равнялась $3.75 \mathrm{~N} / \mathrm{min}$ при скорости перемещения $2.45 \mathrm{~mm} / \mathrm{min}$. Для исследования царапины использовался оптический микроскоп Полар 1 (Микромед, Россия). Коэффициент трения при скретч-тесте определялся как отношение тангенциальной компоненты силы трения к нормальной [12].

Эксперименты показали, что исходный образец стали обладает сравнительно небольшой твердостью (5.5 GPa) и низкими значениями индекса пластичности $(H / E)$, сопротивления пластической деформации $\left(H^{3} / E^{2}\right)$ и упругого восстановления $\left(W_{e}\right)$ (см. таблицу). После обработки в плазме азота твердость поверхности стали увеличивается практически в 3 раза (до $15.6 \mathrm{GPa}$ ), что влечет за собой значительное увеличение $H / E, H^{3} / E^{2}$ и $W_{e}$ (до $0.073,84 \mathrm{MPa}$ и $60 \%$ соответственно). Это связано с образованием на поверхности образца тонких нитридных, оксидных или оксинитридных слоев в результате бомбардировки ионами азота, а также взаимодействия поверхности с кислородом из остаточной атмосферы камеры и паров воды со стенок камеры. Нанесение пленки $a-\mathrm{C}: \mathrm{H}: \mathrm{SiO}_{x}$ на необработанный в плазме азота образец приводит практически к такому же увеличению твердости (до $15.1 \mathrm{GPa}$ ). Но поскольку это сопровождается снижением модуля упругости поверхности до $152 \mathrm{GPa}$, то параметры $H / E, H^{3} / E^{2}$ и $W_{e}$ после 


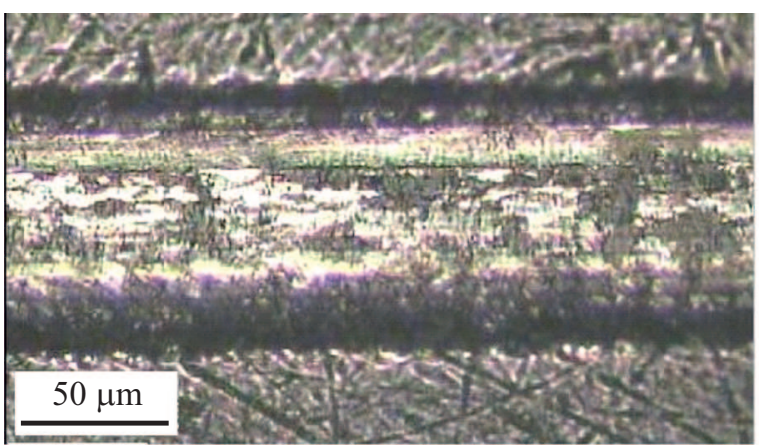

$8.9 \mathrm{~N}$

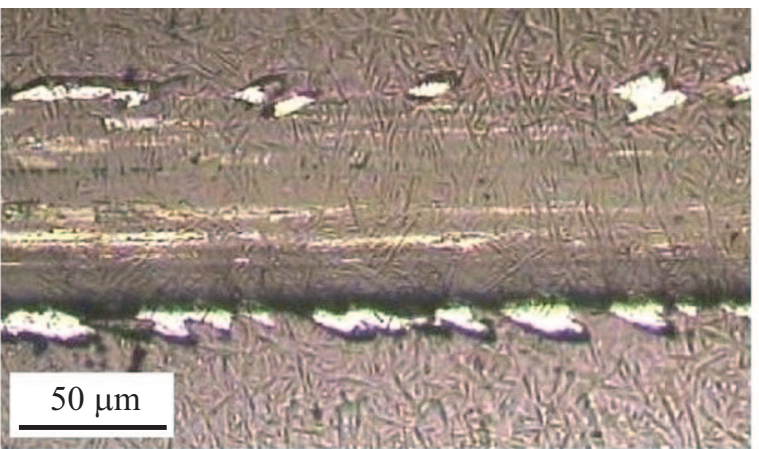

$7.7 \mathrm{~N}$

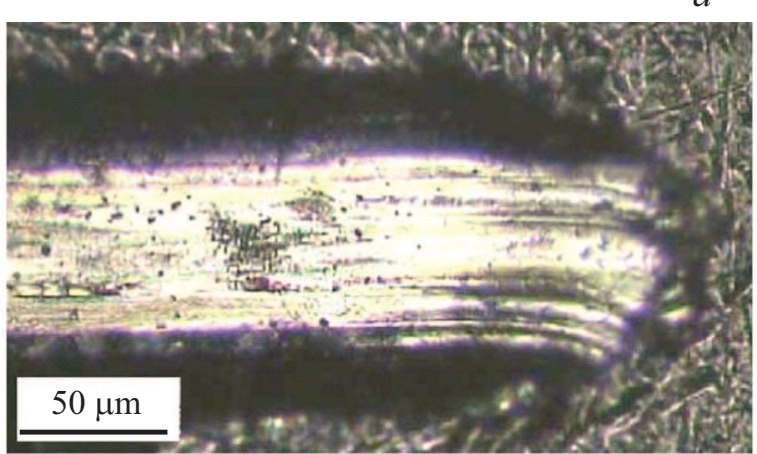

$15 \mathrm{~N}$

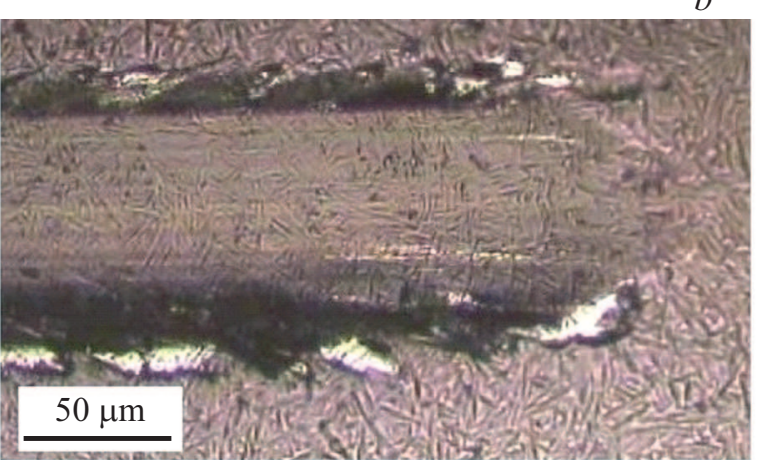

$15 \mathrm{~N}$

Рис. 2. Оптические изображения царапины после проведения скретч-теста на образцах пленки $a$-C : $\mathrm{H}: \mathrm{SiO}_{x}$, нанесенной на сталь марки 316L. $a-$ без предварительной обработки образцов в плазме азота, $b-$ с предварительной обработкой в плазме азота.

нанесения пленки увеличиваются в большей степени (до $0.1,150 \mathrm{MPa} \mathrm{и} 82 \%$ соответственно).

Наибольшее улучшение механических характеристик поверхности стали $316 \mathrm{~L}$ наблюдалось после дуплексной обработки, включающей в себя обработку плазмой азота и нанесение пленки на основе углерода. Если твердость поверхности в результате такой обработки увеличивается всего до $19 \mathrm{GPa}$, то параметры $H / E, H^{3} / E^{2}$ и $W_{e}$ увеличиваются более заметно (до 0.118, $266 \mathrm{MPa} \mathrm{и} \mathrm{95 \%}$ соответственно).

Для тонких пленок и покрытий одним из важнейших параметров является адгезия к подложке. При измерении адгезии методом скретч-теста основное внимание уделяется исследованию царапины и области ее разрушения, а также поведению сигнала акустической эмиссии и коэффициента трения [12]. На рис. 1 и 2 представлены результаты скретч-теста пленки $a-\mathrm{C}: \mathrm{H}: \mathrm{SiO}_{x}$, нанесенной на исходный образец стали марки $316 \mathrm{~L}$ и образец, предварительно обработанный в плазме азота. Из рис. 1, $a$ видно, что увеличение нагрузки на индентор приводит к непрерывному росту коэффициента трения образца без предварительной обработки плазмой азота (до 0.4 при $15 \mathrm{~N}$ ). При нагрузке около $10 \mathrm{~N}$ покрытие практически полностью стирается с подложки. Из рис. $1, b$ видно, что у образца с дуплексной обработкой поверхности сигнал акустической эмиссии слабо изменяется в исследуемом интервале нагрузок на индентор. При нагрузке $15 \mathrm{~N}$ полного разрушения пленки не происходит, о чем свидетельствуют низкие значения коэффициента трения при этой нагрузке и фотографии царапины (рис. 2). Предварительная обработка поверхности в плазме азота способствует значительному повышению адгезии пленок $a-\mathrm{C}: \mathrm{H}: \mathrm{SiO}_{x}$. Это обусловлено тем, что твердость поверхности, на которую наносится защитное покрытие, в 3 раза выше и равна твердости пленки.

Таким образом, данные наноиндентирования и скретчтеста однозначно демонстрируют преимущества дуплексной обработки медицинской стали марки $316 \mathrm{~L}$ с точки зрения улучшения механических свойств поверхности и повышения адгезии защитных пленок $a$-C : $\mathrm{H}: \mathrm{SiO}_{x}$. Данная обработка приводит к повышению твердости поверхности до $19.2 \mathrm{GPa}$, увеличению индекса пластичности (до 0.118), сопротивления пластической деформации (до $266 \mathrm{MPa)} \mathrm{и} \mathrm{упругого} \mathrm{восстановления} \mathrm{(до} \mathrm{95 \% ).}$

\section{Финансирование работы}

Работа выполнена при финансовой поддержке гранта Президента РФ (проект МК-1234.2020.8).

\section{Конфликт интересов}

Авторы заявляют, что у них нет конфликта интересов. 


\section{Список литературы}

[1] Golish S.R., Mihalko W.M. // J. Bone Joint Surg. Am. 2011. V. 93. P. 207-212.

DOI: 10.2106/00004623-201101190-00013

[2] Lepicka M, Gradzka-Dahlke M., Pieniak D., Paserbiewicz K., Niewczas A. // Wear. 2017. V. 382-383. P. 62-70. DOI: 10.1016/j.wear.2017.04.017

[3] Chen Y., Nie X., Leyland A., Housden J., Matthew A. // Surf. Coat. Technol. 2013. V. 237. P. 219-229.

DOI: 10.1016/j.surfcoat.2013.09.029

[4] Constantinou M., Pervolaraki M., Koutsokeras L., Prouskas C., Patsalas P., Kelires P., Giapintzakis J., Constantinides G. // Surf. Coat. Technol. 2017. V. 330. P. 185-195. DOI: 10.1016/j.surfcoat.2017.09.048

[5] Batory D., Jedrzejczak A., Szymanski W., Niedzielski P., Fijalkowski M., Louda P., Kotela I., Hromadka M, Musil J. // Thin Solid Films. 2015. V. 590. P. 299-305.

DOI: $10.1016 /$ j.tsf.2015.08.017

[6] Zavedeev E.V., Zilova O.S., Barinov A.D., Shupegin M.L., Arutyunyan N.R., Jaeggi B., Neuenschwander B., Pimenov S.M. // Diamond Relat. Mater. 2017. V. 74. P. 45-52. DOI: 10.1016/j.diamond.2017.02.003

[7] Jedrzejczak A., Kolodziejczyk L., Szymanski W., Piwonski I, Cichomski M., Kisielewska A., Dudek M., Batory D. // Tribol. Int. 2017. V. 112. P. 155-162. DOI: $10.1016 /$ j.triboint.2017.03.026

[8] Dearnaley G., Arps J.H. // Surf. Coat. Technol. 2005. V. 200. P. 2518-2524. DOI: $10.1016 /$ j.surfcoat.2005.07.077

[9] Boromei I., Ceschini L., Marconi A., Martini C. // Wear. 2013. V. 302. P. 899-908. DOI: 10.1016/j.wear.2013.01.086

[10] Azzia M., Paquette M., Szpunar J.A., Klemberg-Sapieha J.E., Martinu L. // Wear. 2009. V. 267. P. 860-866.

DOI: $10.1016 /$ j.wear.2009.02.006

[11] Grenadyorov A.S., Solovyev A.A., Oskomov K.V., Oskirko V.O. // J. Vac. Sci. Technol. A. 2019. V. 37. P. 061512. DOI: $10.1116 / 1.5118852$

[12] Kataria S., Kumar N., Dash S., Ramaseshan R., Tyagi A.K. // Surf. Coat. Technol. 2010. V. 205. P. 922-927.

DOI: 10.1016/j.surfcoat.2010.08.060 